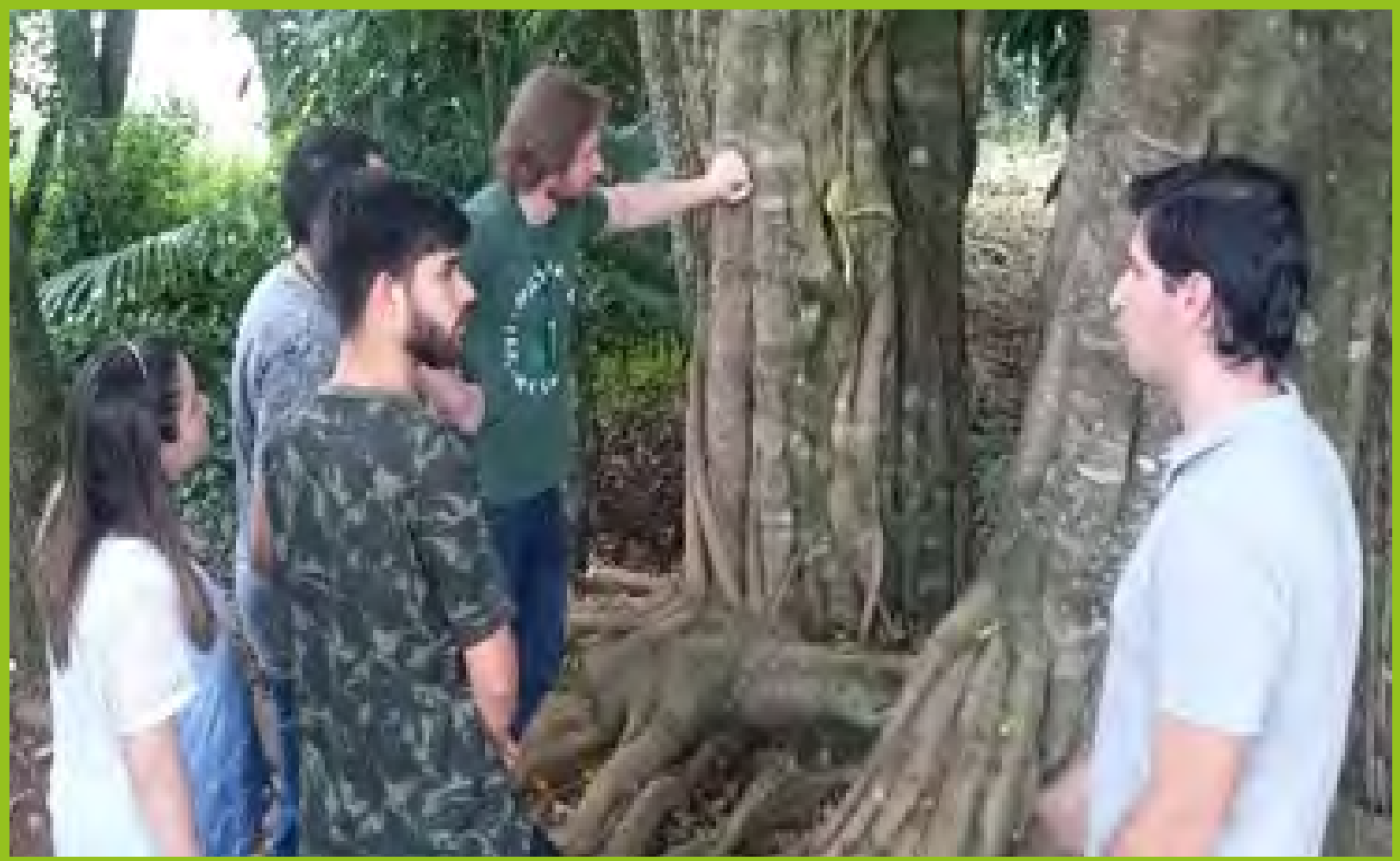

\title{
Mapeamento de abelhas-sem-ferrão em uma Área de Preservação Permanente do Sul do Brasil
}

Anderson José Antonietti - anderson.jose@ifsc.edu.br 1

Mário Cesar Sedrez - mario.sedrez@ifsc.edu.br 2

\section{RESUMO}

Diversos cientistas ao redor do mundo têm alertado sobre a diminuição das populações de abelhas devido às ações antrópicas, como o desmatamento e o uso de agrotóxicos. Preocupados com essa realidade local e mundial, a Fundação Jaraguaense de Meio Ambiente (FUJAMA) solicitou a elaboração do presente estudo em 2018, o qual teve como objetivo mapear e identificar as espécies de abelhas-sem-ferrão (ASF), na comunidade do entorno e na Área de Preservação Permanente (APP) do IFSC Câmpus Jaraguá do Sul-Rau. Para isso, foram confeccionados e instalados ninhos-isca em troncos de árvores de grande porte, à sombra, na APP do câmpus e na área do entorno, em casa de vizinhos da comunidade, sendo inspecionados semanalmente. As espécies de ASF que nidificaram nas iscas foram identificadas e entre 45 e 60 dias, após as capturas, os enxames eram transferidos dos ninhos-isca para as caixas racionais, dando início à estruturação de um meliponário modelo. Foram identificadas três espécies de ASF no entorno, a Jataí (Tetragonisca angustula), a Mirim-guaçu-amarela (Plebeia remota rufis) e a Mirim-droryana (Plebeia droryana). A participação da FUJAMA e os resultados obtidos são um indicativo à realização de futuras ações de extensão, visando a conservação de ASF e a introdução da atividade de meliponicultura na comunidade.

PALAVRAS-CHAVE: abelhas Jataí; abelhas Mirim; ninhos-isca; meliponicultura; conservação da biodiversidade.

1 Mestre em Engenharia Mecânica. Professor do Instituto Federal de Santa Catarina (IFSC), Campus Jaraguá do Sul - RAU.

2 Doutor em Ecologia e Recursos Naturais. Professor do Instituto Federal de Santa Catarina (IFSC), Campus Jaraguá do Sul RAU. 


\title{
Stingless Bee Mapping in a Permanent Preservation Area in Southern Brazil
}

\begin{abstract}
Several scientists around the world have been warning about the bee population decrease due to human actions, such as deforestation and use of pesticides. Concerned with this global and local reality, the Jaraguaense Environment Foundation (FUJAMA) requested the elaboration of this study in 2018, which aimed at mapping and identifying the species of Stingless Bees (ASF) in the surrounding community and in the Area of Permanent Preservation (APP) of IFSC Jaragua do Sul-Rau Campus. For this, bait-nests were made and installed on large tree trunks, in the shade, in the campus APP and in the surrounding area, at neighborhood houses, being inspected weekly. The ASF species that nested in the baits were identified and the swarms were transferred from the bait-nests to the rational boxes 45 to 60 days after the catching, initiating the structuring of a meliponary model. Three ASF species were identified in the surroundings: Jata (Tetragonisca angustula), Mirim-guaçu-amarela (Plebeia remota rufis) and Mirim-droryana (Plebeia droryana). FUJAMA's participation and the results obtained are indicative to future university extension actions, aiming at the conservation of ASF and the introduction of meliponiculture activity in the community.
\end{abstract}

KEYWORDS: Jataí bees; Mirim bees; bait-nests; meliponiculture; biodiversity conservation.

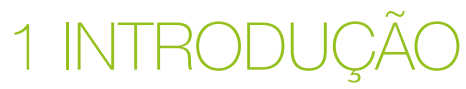

As abelhas são essenciais para a manutenção e equilíbrio dos ecossistemas (DE FREITAS et al., 2020), têm papel fundamental na base das cadeias alimentares e valor imensurável para a biodiversidade e ambientes naturais (IMPERATRIZ-FONSECA et al., 2012). Esses insetos atuam como polinizadores de uma grande variedade de espécies de plantas, incluindo diversas culturas agrícolas de relevância econômica (FONTES, 2019). Estima-se que um terço da alimentação humana dependa direta ou indiretamente da polinização realizada por abelhas, com destaque para os meliponíneos, conhecidas como abelhas-semferrão (ASF) ou abelhas indígenas (VILLAS-BÔAS, 2012).

Segundo esse mesmo autor, as ASF constituem um grupo de abelhas eussociais, diverso e abundante, distribuído principalmente, em regiões tropicais da Terra, como quase toda a América Latina e África, Norte da Austrália e Sudeste Asiático. Ele afirma ainda que as ASF ou nativas estão presentes no Brasil muito antes da exploração comercial das abelhas Apis mellifera (Lineu, 1758), originárias da Europa e África.

Segundo Ballivian (2008), o mel das abelhas nativas caracterizava-se como o principal adoçante natural e desempenhava, juntamente com o pólen, importante papel na dieta das comunidades indígenas americanas. Além da produção de mel e do pólen, Villas-Bôas (2012) destaca como produtos das ASF no Brasil, as colônias e a polinização agrícola comprovada de açaí, berinjela, morango, pimentão e tomate.

Apesar da indiscutível relevância socioambiental e econômica, muitas espécies de ASF estão ameaçadas por ações antrópicas e correm o risco de extinção. Nesse sentido, Proní (2000) aponta que diversos fatores têm contribuído para a diminuição das populações de abelhas, como o uso indiscriminado de agrotóxicos, as alterações de habitat pelo desmatamento e queimadas, a crescente urbanização, a ação predatória dos meleiros e até o combate pelos apicultores por considerarem-nas competidoras da A. mellifera.

Por outro lado, por não terem capacidade de ferroar e geralmente não serem agressivas, as ASF são facilmente encontradas nas propriedades rurais (RODRIGUES, 2006) e criadas de forma racional (DE FREITAS et al., 2020). Assim, surgem os meliponários, como uma forma de proteção e conservação da grande diversidade de espécies de ASF.

Os meliponários correspondem aos locais onde as colmeias de meliponíneos são instaladas, principalmente, para dar conforto às abelhas e facilitar o trabalho do meliponicultor (CONTRERA; MENEZES; VENTURIERI, 2011; VILLAS-BÔAS, 2012). Já, a sua implantação, a utilização das abelhas silvestres nativas e a comercialização de seus produtos constitui a meliponicultura, regulamentada pela Resolução CONAMA no 496, de 19 de agosto de 2020 (MMA, 2020). De acordo com Fontes (2019), a atividade da meliponicultura é economicamente vantajosa, pois não exige grandes investimentos e oferece uma grande variedade de produtos, como o mel e cerume, o pólen, a própolis e a geoprópolis. 
Neste contexto e preocupados com essa realidade local e mundial das abelhas, representantes da Fundação Jaraguaense de Meio Ambiente (FUJAMA) e da Câmara de Vereadores de Jaraguá do Sul reuniramse com a gestão e membros da Comissão do IFSC Sustentável, incluindo servidores e discentes, do IFSC Câmpus Jaraguá do Sul - Rau e solicitaram, através de uma carta demanda, a elaboração de um projeto sobre ASF, pois a FUJAMA possui interesse em apoiar projetos de educação ambiental para a comunidade, tendo como tema norteador a conservação da biodiversidade.

Somados a isso, estudos prévios reforçam a importância de se realizar projetos que envolvam estudos com ASF na educação, pensando-se não só na conservação das espécies e na estabilidade dos ecossistemas, mas, principalmente, na possibilidade de interação entre ensino, pesquisa e extensão, na perspectiva de se buscar o estreitamento das relações com a comunidade escolar (TAVARES et al., 2016).

Assim surgiu o presente estudo, como parte do projeto de extensão "Abelhas nativas sem ferrão: conservação, inserção e expansão na comunidade do entorno e na Área de Preservação Permanente (APP) do IFSC Câmpus Jaraguá do Sul - Rau", que teve como objetivo mapear e identificar espécies de ASF, na comunidade do entorno e na APP do IFSC Câmpus de Jaraguá do Sul - Rau.

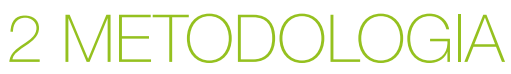

A metodologia aplicada no mapeamento das espécies de abelhas-sem-ferrão seguiu as orientações da Resolução №61/2016-CONSUP/IFSC (IFSC, 2016). Envolveu a realização de reuniões de planejamento, a delimitação da área de estudos, a obtenção de materiais, a confecção e instalação de ninhos-isca e caixas racionais, a identificação e a transferência das espécies capturadas para as caixas racionais, dando início à estruturação de um meliponário modelo.

\section{1 Ärea de Estudos}

0 presente estudo foi realizado de agosto/2018 a dezembro/2019, no entorno e em uma área verde de APP, remanescente de Mata Atlântica, com aproximadamente 5000 m2, pertencente ao IFSC Câmpus Jaraguá do Sul - Rau (26²8’05.3”S e 4906’50.6”W) e localizado na região Norte de Santa Catarina, Brasil (Fig. 1).

Figura 1 - Localização da área de estudo - Entorno e APP do IFSC Câmpus Jaraguá do Sul - Rau, região Norte de Santa Catarina, Brasil.
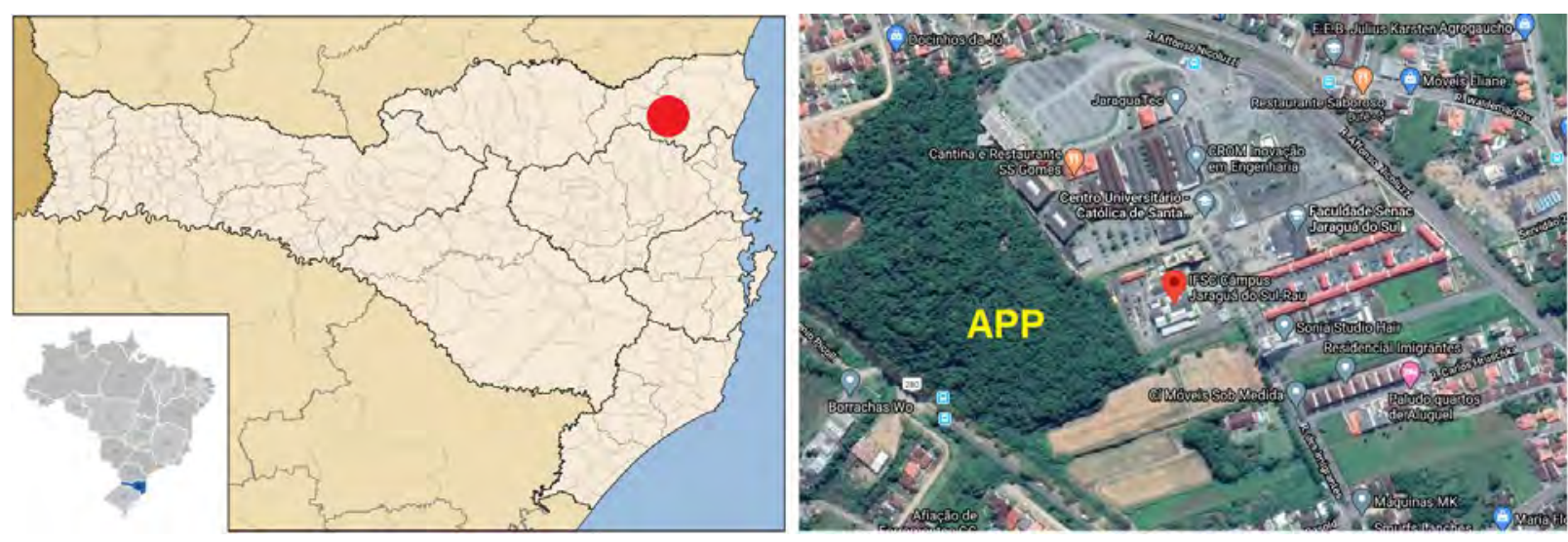

FONTE: Elaborada pelos autores, adaptada de Google Maps (2020)

\subsection{Participação dos discentes e da Comunidade}

Em todas as atividades houve o protagonismo dos discentes extensionistas que participaram efetivamente da elaboração do projeto, desenvolveram a pesquisa através de uma ampla revisão bibliográfica sobre a biologia das abelhas sem ferrão, sua importância para o meio ambiente e sua utilização como fonte alternativa de renda e transformação social.

Os discentes atuaram também na confecção de materiais (ninhos-isca e caixas racionais), trabalhos de campo, visitas à comunidade externa (Fig. 2a), palestras na Semana Nacional de Ciência e Tecnologia (SNCT), em 2019 (Fig. 2b) e na preparação do relatório final das atividades. 
Figura 2 - Participação dos discentes nas ações de extensão. (a) Visita a um quintal agroflorestal.

(b) Palestra realizada na SNCT/2019.

(a)

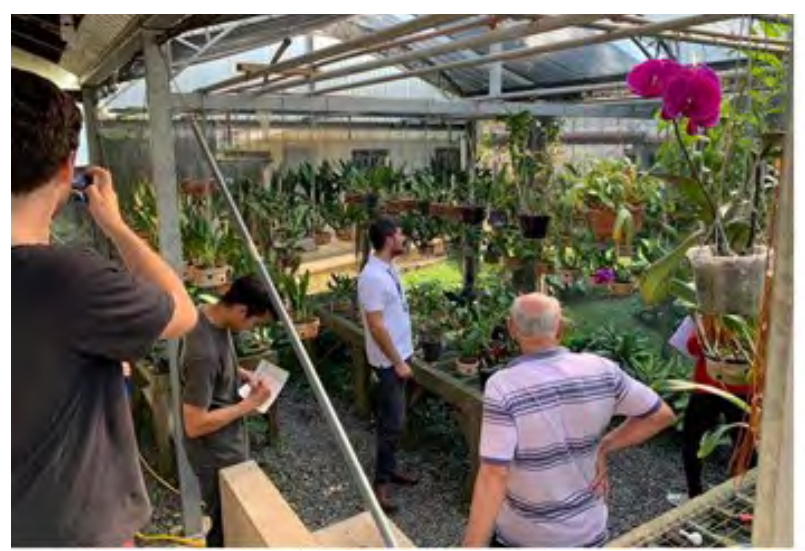

(b)

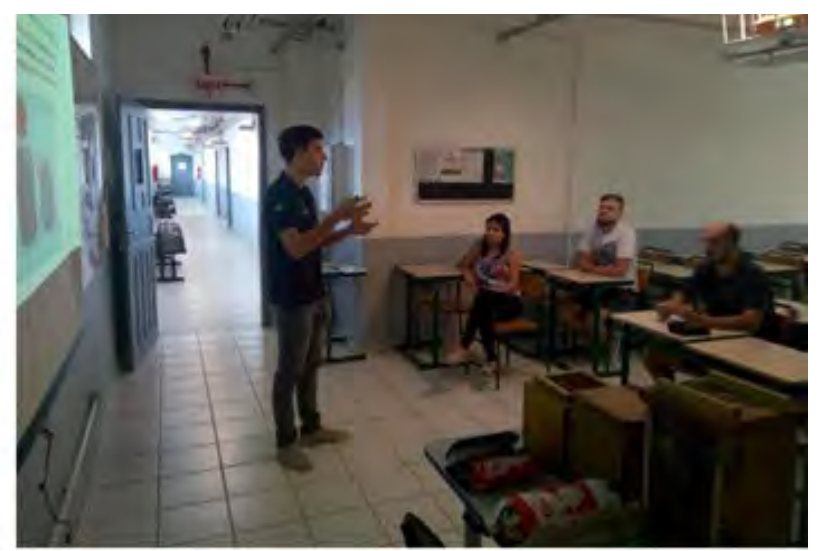

FONTE: Fotografia dos autores (2019).

As palestras para a comunidade interna e externa, interessadas no conhecimento sobre abelhas-semferrão e a meliponicultura, foram preparadas e apresentadas pelos docentes e discentes extensionistas, utilizando-se slides e projetor multimídia. Todas essas atividades demonstraram a participação efetiva dos discentes como protagonistas da atividade impactando fortemente em seu processo formativo.

Além disso, houve interação dialógica entre professores, servidores técnico-administrativos e membros da comunidade externa, como a Fundação Jaraguaense de Meio Ambiente (FUJAMA), Câmara de Vereadores e apoio substancial da gestão do IFSC Câmpus Jaraguá do Sul - Rau (Fig. 3).

Figura 3 - Participação da comunidade. (a) Reunião com FUJAMA e Vereadores. (b) Visita à Grameira.

(a)

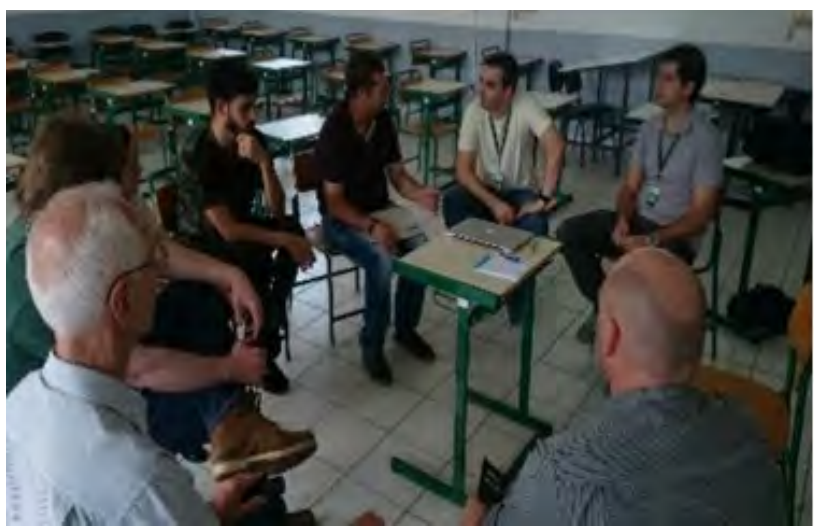

(b)

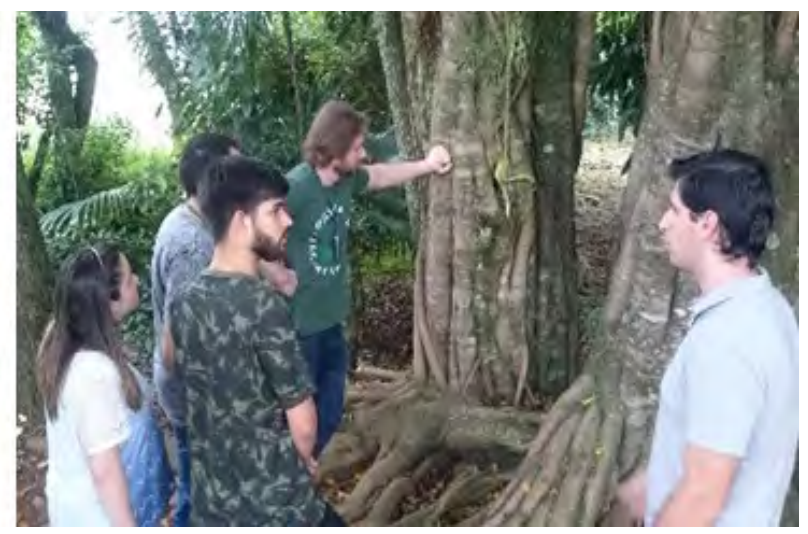

FONTE: Fotografia dos autores (2018).

A avaliação e o acompanhamento do projeto deram-se de forma contínua, principalmente nas reuniões semanais com a equipe executora e a participação da comunidade. As atividades desenvolvidas foram registradas através de fotos e na forma de um relatório final, encaminhado à PROEX, culminando com este artigo científico. Os resultados e conclusões deste trabalho serão divulgados à comunidade, em eventos futuros como a SNCT e o SEPEl.

\subsection{Ninhos-Iscas, Caixas Racionais e Capturas}

Para o trabalho de campo, os ninhos-isca foram confeccionados pelos discentes a partir de materiais reciclados doados pela comunidade, como as garrafas pet de dois litros, embalagens de leite longa vida ou "tetrapak" (camadas de papel, alumínio e plástico), além de fita adesiva e plástico preto (lona). 0 interior do ninho-isca foi banhado com um líquido liberador de feromônios, composto por álcool, cera e própolis, com o objetivo de atrair os enxames de ASF. 
Os ninhos-isca foram instalados em troncos de árvores de grande porte, à sombra, na área do entorno, em casa de vizinhos da comunidade e na APP do IFSC Câmpus de Jaraguá do Sul - Rau, sendo inspecionados semanalmente (Fig. 4).

Figura 4 - Ninho-isca instalado no entorno da APP do IFSC Câmpus Jaraguá do Sul - Rau.

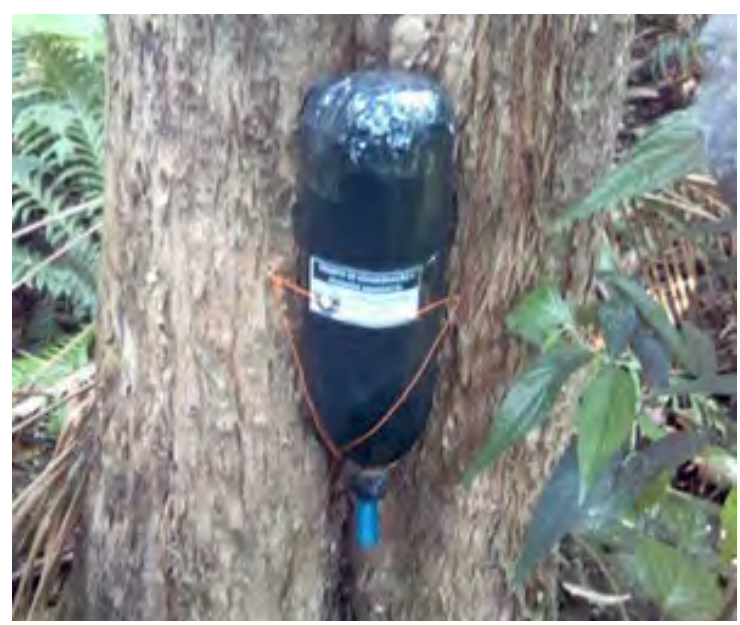

FONTE: Fotografia dos autores (2018).

As espécies de ASF que nidificaram nas iscas foram identificadas de acordo com o catálogo de Moure et al. (2012). Entre 45 e 60 dias, após as capturas, os enxames de ASF eram transferidos dos ninhos-isca para as caixas racionais, dando preferência aos dias ensolarados, entre oito e onze horas da manhã VillasBôas (2012).

As caixas racionais, modelo INPA, desenvolvidas pelo Instituto Nacional de Pesquisas da Amazônia, destinadas ao acondicionamento final dos enxames, foram fabricadas seguindo o modelo ilustrado por Venturieri (2008) e Villas-Bôas (2012). Venturieri (2004) corrobora que essas caixas facilitam a multiplicação dos ninhos e a colheita do mel, não sendo recomendada a sua pintura quando se quer produzir mel orgânico. Esse modelo de caixa racional foi utilizado, pois além de servir de abrigo, facilita o manejo das colmeias, quando se pretende realizar inspeções.

Para Venturieri (2004; 2008), a caixa racional é considerada o item mais importante para o criador e deve ser de madeira que não empene, bem seca, resistente a cupins e leve. Sendo assim, as caixas foram construídas com espessura igual ou superior a quatro centímetros, para aumentar a resistência às intempéries e garantir às colmeias o conforto térmico necessário. Foram confeccionadas com módulos sobrepostos (Fig. 5a), sendo compostas de dois ou três compartimentos (ninho, sobreninho e melgueira), além da tampa, e com dimensões internas adequadas à espécie de ASF (Fig. 5b), pois cada espécie tem uma arquitetura específica para o seu ninho (DE FREITAS et al., 2020).

Figura 5 - Construção de caixas racionais: (a) Caixa racional pronta, com tampa e três módulos (ninho, sobreninho e melgueira). (b) Interior dos módulos ninho e sobreninho.

(a)

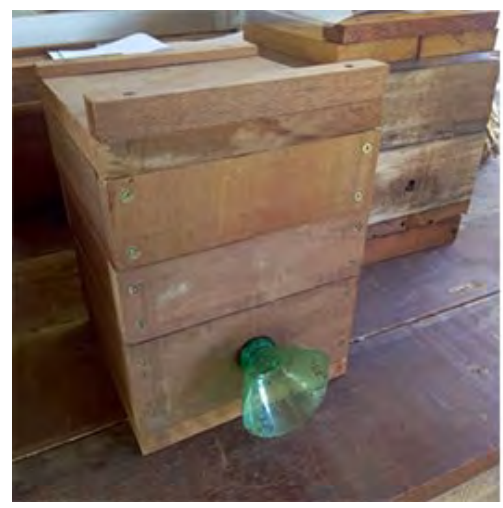

(b)

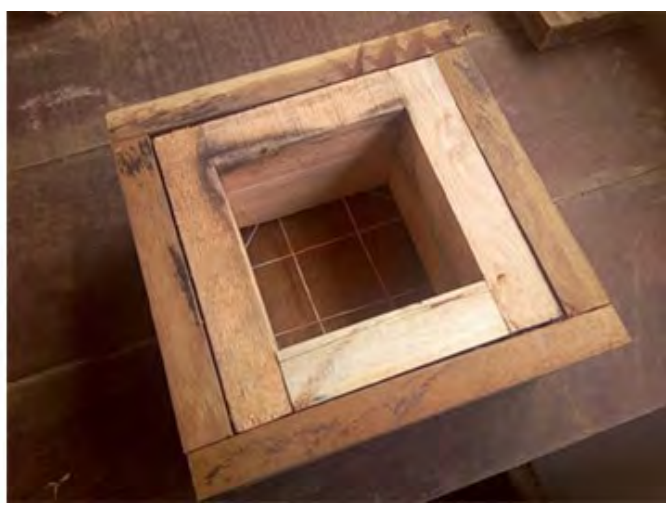

FONTE: Fotografia dos autores (2019). 
Uma importante orientação de Villas-Bôas (2012) é que tanto a captura quanto a transferência de ASF ocorram, preferencialmente, em dias ensolarados, entre as $8 \mathrm{~h}$ e $11 \mathrm{~h}$. Na sua transferência pode-se remover um pouco do cerume do invólucro da colônia e colocar pelo lado de fora da entrada da caixa, o que auxilia as operárias-guarda e forrageiras, em sua orientação (CONTRERA; VENTURIERI, 2008). Villas-Bôas (2012) ainda reforça que para se evitar a vulnerabilidade às pragas, nos momentos que sucedem uma captura, transferência ou divisão, recomenda-se a diminuição do tamanho do orifício de entrada do ninho-isca ou da caixa racional com cerume.

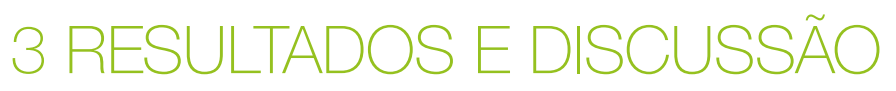

Durante o período de desenvolvimento deste projeto de extensão foram confeccionados aproximadamente 40 ninhos-isca, tecnicamente idênticos aos registrados na Figura 6a, e instalados pelos discentes (Fig. 6b) no entorno e na Área de Preservação Permanente (APP)do IFSC Câmpus Jaraguá do Sul - Rau.

Figura 6 - Confecção e instalação de ninhos-isca. (a) Ninho-isca instalado à sombra em árvore de grande porte. (b) Discentes instalando um ninho-isca na APP do IFSC Câmpus Jaraguá do Sul-Rau.

(a)

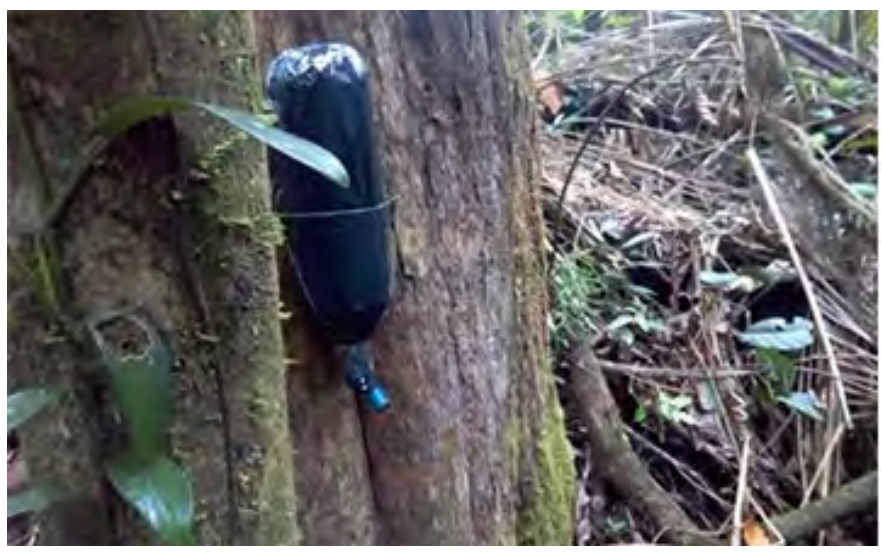

(b)

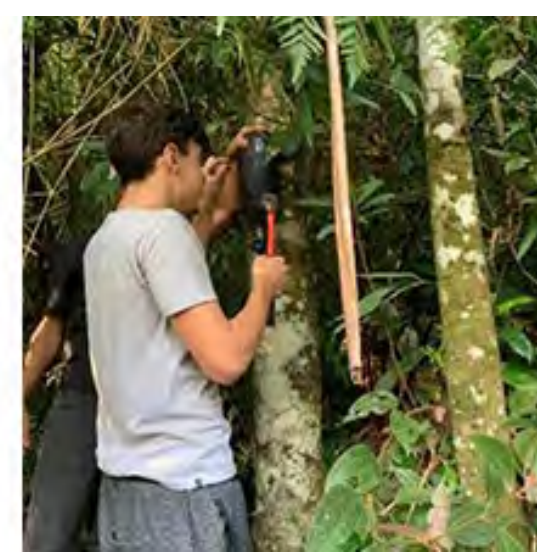

FONTE: Fotografia dos autores (2019).

Os ninhos-isca ou ninhos-armadilha representam uma alternativa interessante para os criadores, pois facilitam o processo de captura e posterior deslocamento dos enxames (OLIVEIRA et al., 2009). Além disso, esse método não agride o meio ambiente por se beneficiar do processo natural de enxameação das ASF. A enxameação é um processo costumeiro de multiplicação das colônias de abelhas verdadeiramente sociais (OLIVEIRA et al., 2009).

No Sul do Brasil, a enxameação tem início na primavera e término em meados do verão (BLOCHTEIN, 2008). Portanto, o mapeamento das ASF foi iniciado na primeira quinzena de agosto/2018, com a instalação dos ninhos-isca, ficando restrita à APP do IFSC Câmpus Jaraguá do Sul - Rau e parte de seu entorno, conhecida como Grameira, destacada na Figura 7.

Figura 7 - Localização da APP do IFSC Câmpus Jaraguá do Sul - Rau e parte de seu entorno, a Grameira.

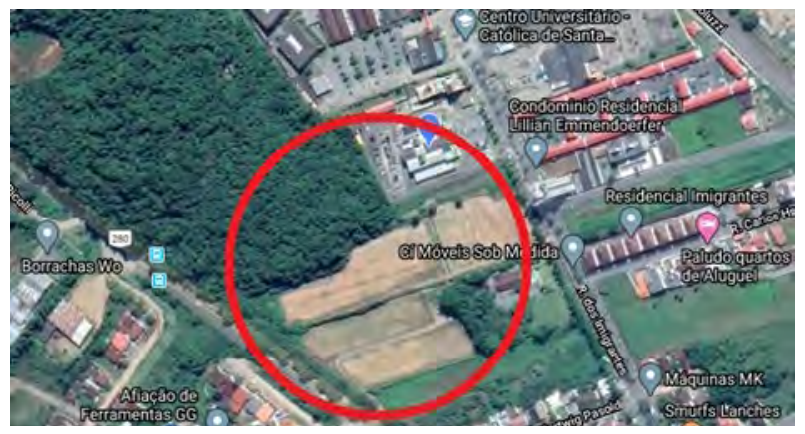

FONTE: Elaborada pelos autores, adaptada de Google Maps (2020). 
As primeiras capturas foram confirmadas na segunda quinzena de setembro/2018, com duas enxameações da espécie Tetragonisca angustula (Latreille, 1811), popularmente conhecida como abelha Jataí (Fig. 8).

Figura 8 - Tetragonisca angustula. Capturas com ninhos-isca.

(a)

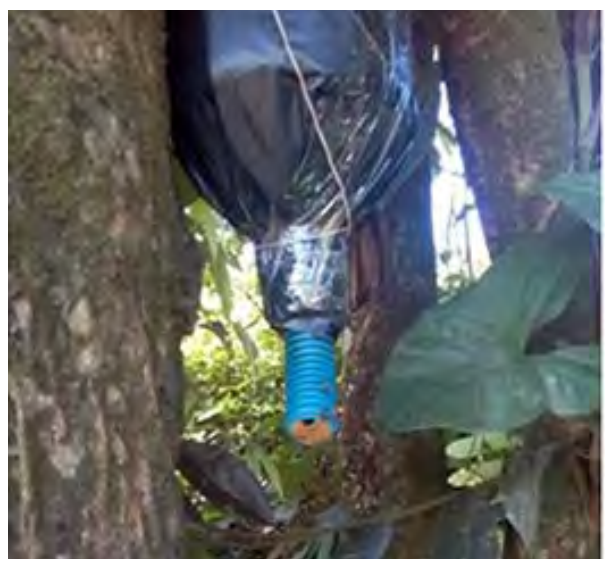

(b)

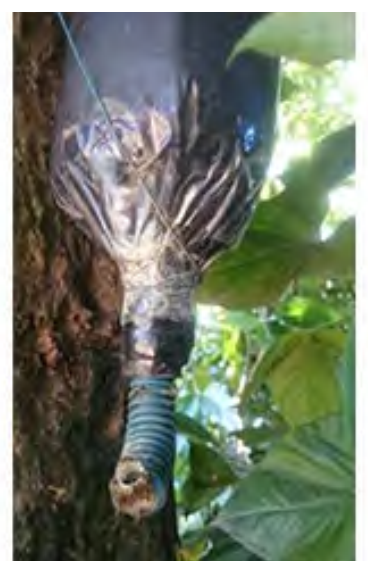

(c)

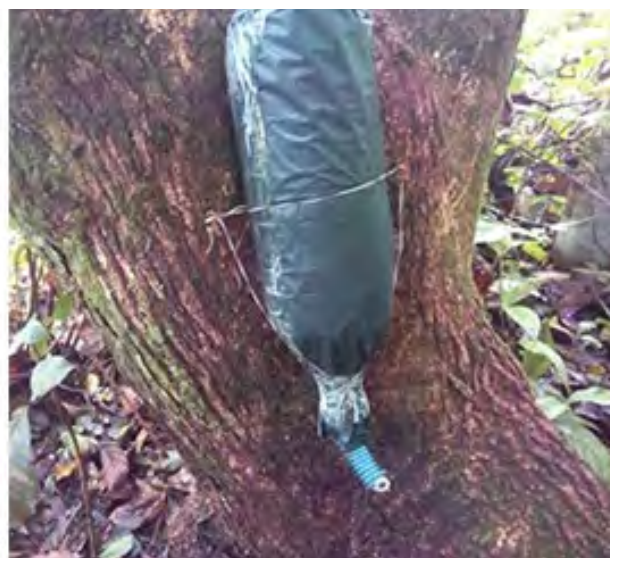

FONTE: Fotografia dos autores (2018).

A abelha T. angustula é a que apresenta a maior incidência, desde o Sul até o Norte do Brasil (BALLIVIAN, 2008). Porém, a ocorrência de chuvas prolongadas e dias frios nos meses de outubro e novembro/2018 prejudicaram as capturas já efetuadas. 0 excesso de chuvas logo após o processo de enxameação é prejudicial para o desenvolvimento da nova colmeia, pois inviabiliza o trabalho das abelhas coletoras.

No início de dezembro/2018, uma segunda espécie de ASF foi identificada no entorno. Tratava-se de uma Plebeia remota rufis (Holmberg, 1903), conhecida como Mirim-guaçu-amarela (Fig. 9). Observou-se que algumas abelhas desta espécie permaneceram ocupando o interior do ninho-isca durante toda a temporada de capturas sem efetivar a enxameação.

\section{Figura 9 - Indício de enxameação de Plebeia remota rufis.}

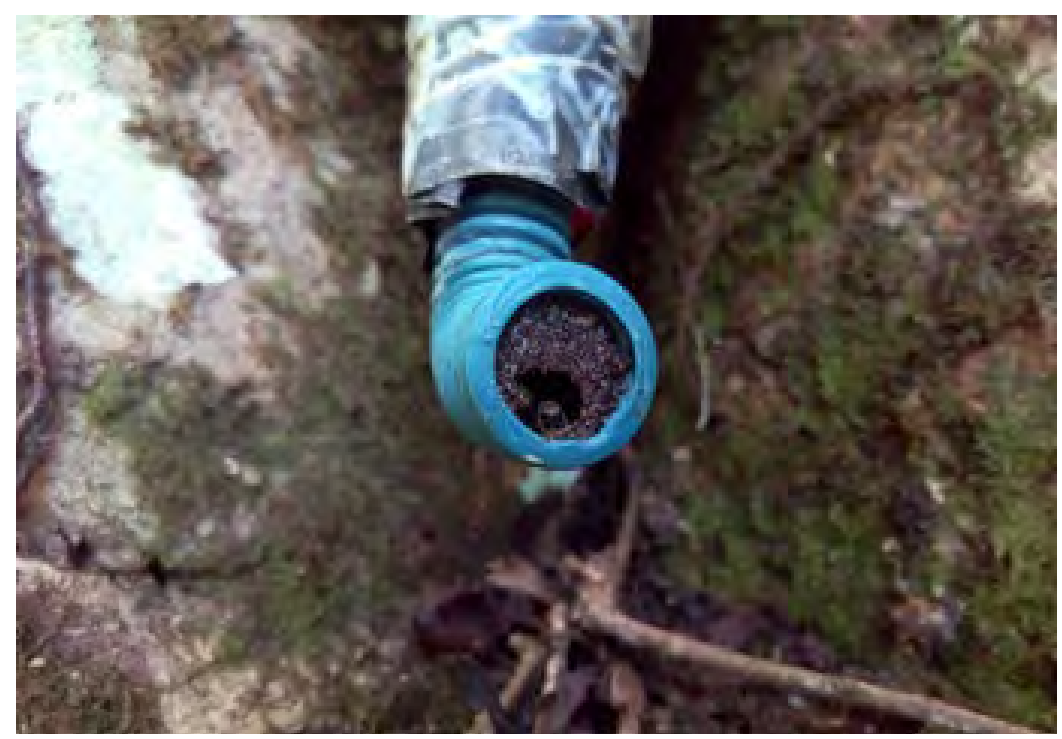

FONTE: Fotografia dos autores (2018).

Apesar de não terem sido constatadas em ninhos-isca, a espécie Plebeia droryana (Friese, 1900), popularmente conhecida como Mirim-droryana, também está presente na área de estudos. A presença de uma colmeia natural dessa espécie em uma árvore é o indicativo de que encontram nesta área as condições necessárias para sua sobrevivência (Fig. 10). Além disso, esse fato observado dá indícios de que outras espécies de ASF, não identificadas no mapeamento, podem estar presentes nesta área de estudos. 
Figura 10 - Diferentes aspectos de um mesmo ninho natural de Plebeia droryana.

(a)

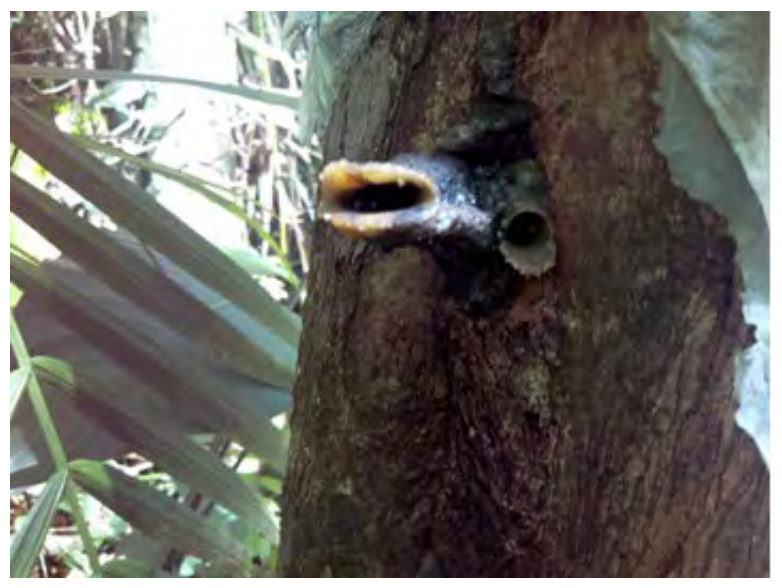

(b)

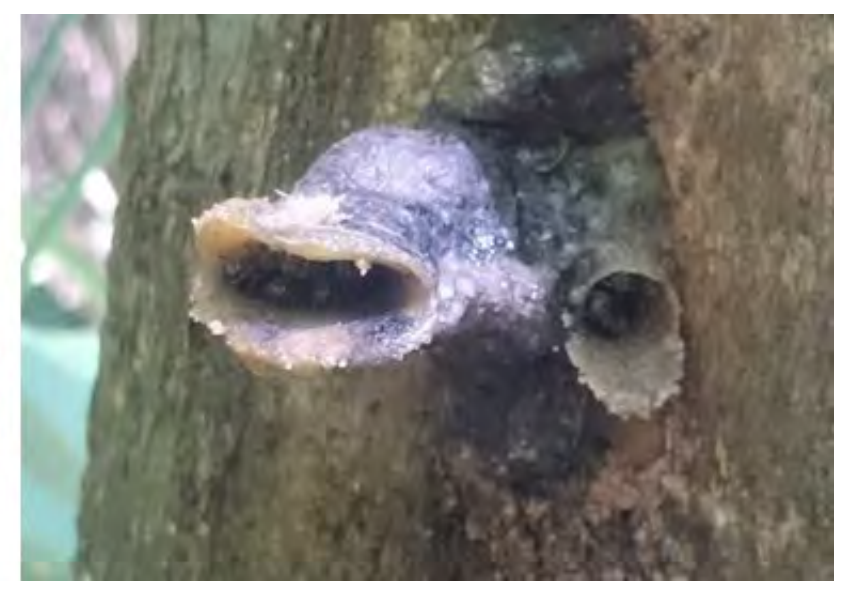

FONTE: Fotografia dos autores (2018).

Ao final da temporada 2018 foram capturados cinco enxames de Jataí e constatados três indícios de captura de Mirim-guaçu, sendo que nenhum dos três indícios resultou em captura de enxame.

Num segundo momento, em setembro/2019, iniciou-se um novo período de capturas com o objetivo de aumentar a área de abrangência e se verificar a presença de outras espécies até $1000 \mathrm{~m}$ do entorno (Fig. 11). Nesta área foram registradas doze capturas de Jataí e outros dois indícios de captura de Mirim-guaçu.

Figura 11 - Região de mapeamento na segunda temporada.

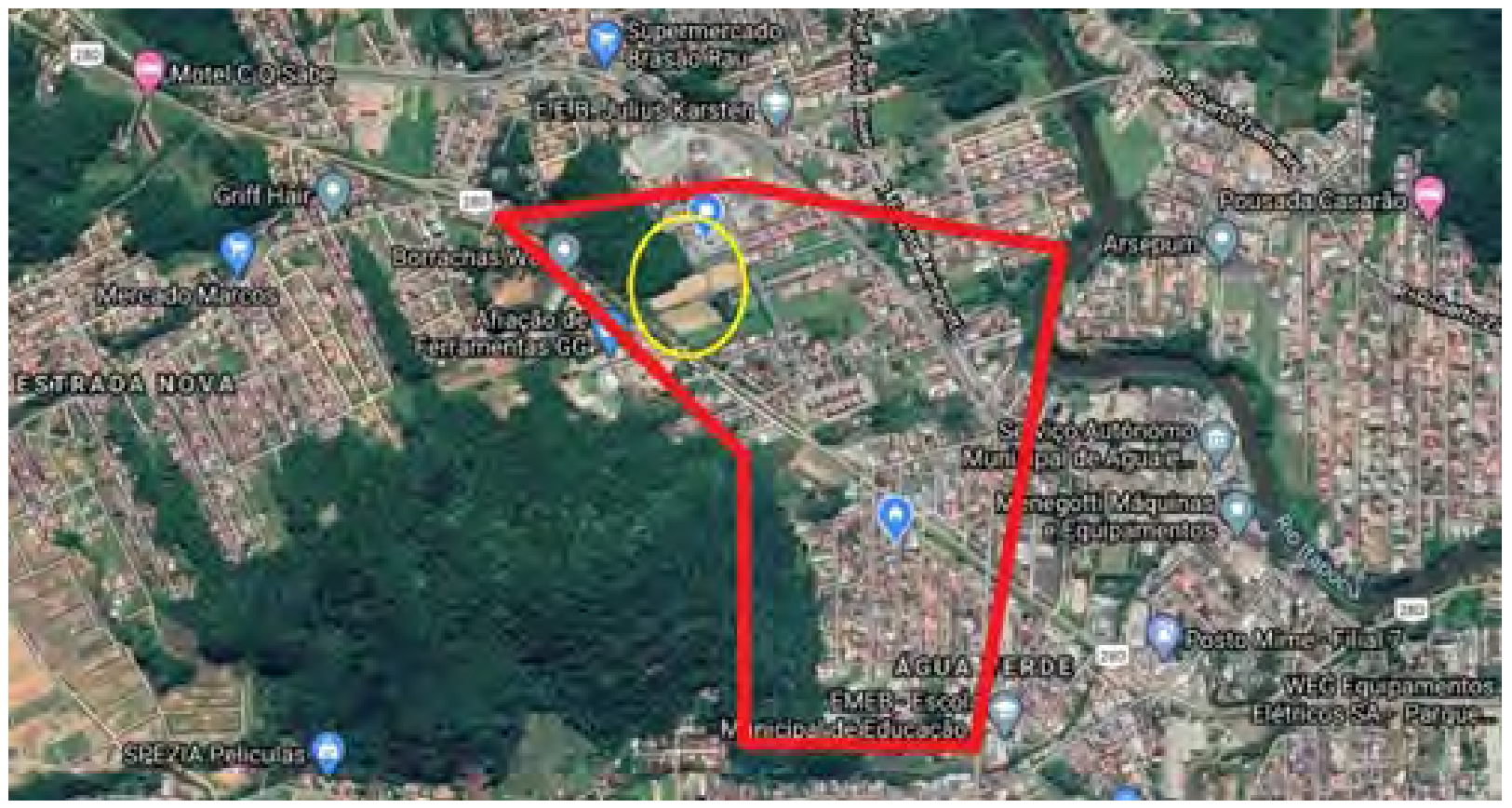

FONTE: Elaborada pelos autores, adaptada de Google Maps (2020).

Todos os enxames capturados ficaram igualmente de 45 a 60 dias no local de captura. Após esse período foram transportados para o local destinado ao meliponário no IFSC Câmpus Jaraguá do Sul - Rau e efetuada a transferência para as caixas racionais (Fig. 12). 
Figura 12 - Transferência de um enxame de Jataí do ninho-isca para a caixa racional. (a) Ninho-isca nidificado. (b) Transferência executada. (c) Caixa racional instalada no meliponário.

(a)

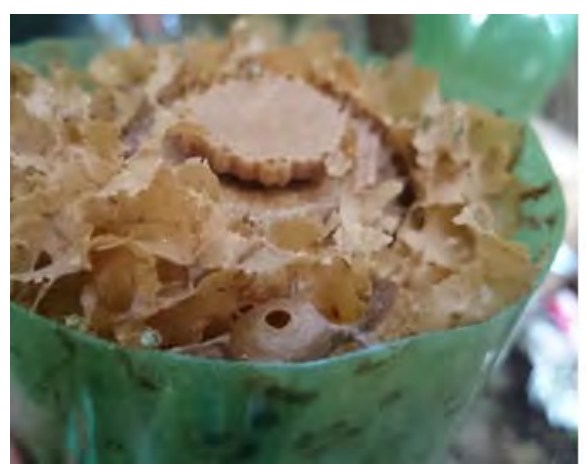

(b)

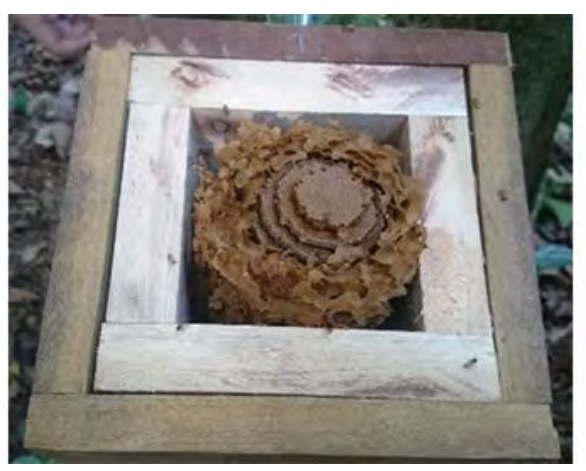

(c)

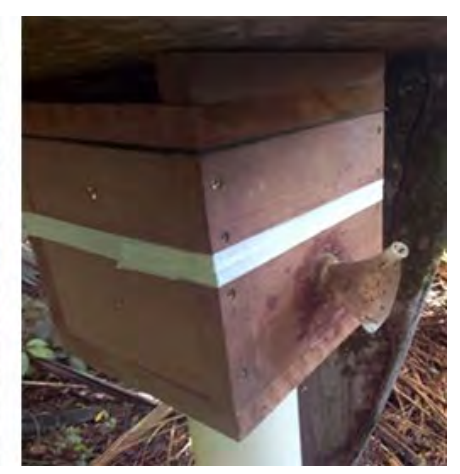

FONTE: Fotografia dos autores (2019).

Os enxames capturados e devidamente transferidos deram início à estruturação de um meliponário modelo que foi instalado no IFSC Câmpus Jaraguá do Sul - Rau. Este meliponário pretende servir como modelo de conservação, inserção e disseminação das espécies de abelhas nativas sem ferrão na comunidade interna e externa, apresentando a atividade da meliponicultura também como uma fonte alternativa de renda e de transformação social para a comunidade onde o IFSC está inserido. Além disso, poderá ser utilizado como laboratório de futuros cursos de Formação Inicial e Continuada (FICs) sobre Meliponicultura Conservacionista, impulsionando a atividade com o fim de contribuir para a conservação das espécies de ASF.

Futuramente, com a implantação do meliponário modelo, projetos de pesquisa poderão ser propostos e executados pelos alunos da disciplina de Fenômenos de Transporte do curso de Engenharia Elétrica, com o objetivo de se desenvolver métodos eficazes para o aquecimento das colmeias, procedimento que auxilia na preservação e manutenção do enxame nas épocas mais frias do ano.

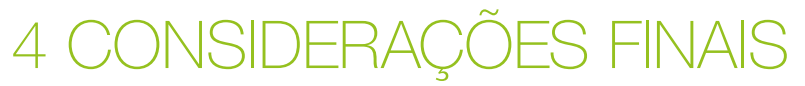

De acordo com este mapeamento de abelhas-sem-ferrão (ASF) foram encontradas apenas três espécies de abelhas com ocorrência natural na área de estudo: a Jataí (Tetragonisca angustula), a Mirimguaçu-amarela (Plebeia remota rufis) e a Mirim-droryana (Plebeia droryana). Porém, não se pode concluir que as outras espécies nativas da região não estejam presentes ou que foram definitivamente extintas. Por outro lado, é uma evidência da diminuição de ninhos naturais ou da falta de ambiência para essas e outras espécies nesta área de estudos.

0 desenvolvimento deste projeto garantiu o início da criação de um meliponário modelo, instalado na APP do IFSC Câmpus Jaraguá do Sul - Rau e terá grande importância, pois permitirá o desenvolvimento de atividades de educação ambiental através de atividades de ensino, pesquisa e extensão, com o viés na transformação social. Dessa forma, a utilização do meliponário poderá propiciar novos conhecimentos e práticas educativas à comunidade interna e externa, através da criação, manejo e conservação de ASF, servindo de modelo para promover ações socioambientais sustentáveis, e a indissociabilidade entre ensino, pesquisa e extensão, em consonância com os Objetivos do Desenvolvimento Sustentável.

0 envolvimento dos discentes ocorreu tanto na pesquisa quanto na execução das ações de extensão para que adquirissem experiências e pudessem atuar como disseminadores da cultura à sustentabilidade. Este trabalho envolveu também a Comissão local do IFSC Sustentável, comunidade externa, docentes e servidores técnico-administrativos na construção e aplicação de novos conhecimentos do interesse da comunidade onde estão inseridos e atendeu uma demanda importante para a sociedade no que se refere a ações de sustentabilidade e que pudessem atuar como disseminadores da cultura da sustentabilidade.

Este projeto esteve articulado ao trabalho coletivo, interdisciplinar e às temáticas desenvolvidas nos cursos subsequentes e de graduação, associados às unidades curriculares como Tecnologia e Meio Ambiente, Gerenciamento Ambiental e Biologia, bem como esteve relacionado com Educação Ambiental, tema transversal que permeia as ações educativas no Câmpus.

Neste sentido, pensando-se em futuros projetos de recuperação ambiental para a inserção e conservação de ASF, vislumbra-se a continuidade da parceria com a Fundação Jaraguaense de Meio Ambiente (FUJAMA), bem como a possibilidade de inclusão do Serviço Autônomo Municipal de Água e Esgoto (SAMAE), que atua na Revitalização da Mata Ciliar do Rio Itapocu. 


\section{REFERENCIAS}

BALLIVIAN, José Manoel P. P. Abelhas nativas sem ferrão. São Leopoldo: Oikos, 2008.

BLOCHTEIN, Betina; et al. Manual de boas práticas para a criação e manejo racional de abelhas sem ferrão no RS: guaraipo, manduri e tubuna. Porto Alegre: Edipucrs, 2008.

CONTRERA, Felipe Andrés León; MENEZES, Cristiano; VENTURIERI, Giorgio Cristino. New horizons on stingless beekeeping (apidae, Meliponini). R. Bras. Zootec., v.40, p.48-51, 2011.

DE FREITAS, Paulo Vitor Divino Xavier de; et al. Noções básicas para criação de abelhas nativas: alimentação e multiplicação. Research, Society and Development, v. 9, n. 4, p. e44942815, 2020. DOI: http://dx.doi. org/10.33448/rsd-v9i4.2815

FONTES, Felipe Mendes. Importância Ecológica das Abelhas: Percepção de Estudantes de Escolas Rurais do Baixo São Francisco Sergipano. 2019. 79 p. Dissertação (Mestrado em Saúde e Ambiente) - Programa de PósGraduação em Saúde e Ambiente, Universidade Tiradentes, Aracajú, 2019.

IFSC. INSTITUTO FEDERAL DE SANTA CATARINA. Resolução CONSUP no 61, de 12 de dezembro de 2016. Regulamenta as Atividades de Extensão no IFSC. 2016. Disponível em: <http://cs.ifsc.edu.br/portal/files/ consup_resoluca061_2016_extensao.pdf>. Acesso em:16/04/2021.

IMPERATRIZ-FONSECA, Vera Lúcia; et al. Desaparecimento das abelhas meliferas e a perspectiva do uso de outras abelhas na polinização. Documentos. Petrolina: Embrapa Semiárido, v. 249, p. 213-226, 2012.

MMA. Ministério do Meio Ambiente. Resolução CONAMA no 496, de 19 de agosto de 2020. Disponível em: < http://www2.mma.gov.br/port/conama/legiabre.cfm?codlegi=747 >. Acesso em: 16/04/2021.

MOURE, Jesus Santiago; URBAN, Danúncia; MELO, Gabriel Augusto Rodrigues de. Ed. 2012. Catalogue of Bees (Hymenoptera, Apoidea) in the Neotropical Region - online version. Disponível em: <http://moure.cria.org.br/ catalogue>.

OLIVEIRA, Ricardo Caliari; et al. Como obter enxames de abelhas sem ferrão na natureza. Mensagem Doce, v. 100, p. 1-6, 2009.

PRONÍ, Edson Aparecido. Biodiversidade de abelhas indígenas sem ferrão (Hymenoptera: Apidae: Meliponinae) na bacia do rio Tibagi, Estado do Paraná, Brasil. Arquivos de Ciências Veterinárias e Zoologia da UNIPAR, v. 3 , n. 2,2000 .

RODRIGUES, Arnaldo dos Santos. Até quando o etnoconhecimento sobre as abelhas sem ferrão (Hymenoptera, Apidae, Meliponinae) será transmitido entre gerações pelos índios Guarani M'byá da Aldeia Morro da Saudade, localizada na cidade de São Paulo, Estado de São Paulo, Brasil? Sitientibus Ser. Ciênc. Biol., v. 6, n. 4, p. 343350, 2006.

TAVARES, Mara Garcia; et al. Abelhas sem ferrão: educação para conservação-interação ensino-pesquisaextensão voltada para o ensino fundamental. Revista Brasileira de Extensão Universitária, v. 7, n. 2, p. 113-120, 2016. DOl: https://doi.org/10.36661/2358-0399.2016v7i2.3128

VENTURIERI, Giorgio Cristino. Criação de Abelhas Indígenas sem Ferrão. Belém: Embrapa Amazônia Oriental, 2008.

VENTURIERI, Giorgio Cristino. Meliponicultura I: caixa racional de criação. Belém: Embrapa Amazônia Oriental, 2004.

VENTURIERI, Giorgio Cristino.; CONTRERA, Felipe Andrés León. Vantagens e limitações do uso de abrigos individuais e comunitários para a abelha indígena sem ferrão uruçu-amarela (Melipona flavolineata). Belém: Embrapa Amazônia Oriental, 2008.

VILLAS-BÔAS, Jerônimo. Manual Tecnológico: mel de abelhas sem ferrão. Brasília: Instituto Sociedade, População e Natureza, 2012. 